\title{
A interlocução com os pares na formação profissional e a construção da identidade do professor-autor-formador
}

\author{
Everton Vargas da Costa ${ }^{1}$ \\ Departamento de World Languages, Framingham State University, Framingham, MA, EUA
}

Margarete Schlatter ${ }^{2}$

Departamento de Línguas Modernas, Universidade Federal do Rio do Sul, Porto Alegre, RS, Brasil

Resumo: $O$ presente trabalho analisa a construção da identidade do professor-autor-formador em um contexto acadêmico de indução à prática docente, à reflexão continuada sobre as práticas e ao registro escrito de atividades pedagógicas visando a promover o diálogo e a troca de conhecimentos com os pares e a comunidade profissional mais ampla. Desde uma perspectiva de formação de professores como uma prática social emergente das interações entre professores (NÓVOA, 1995; PÉREZ-GÓMEZ, 1995; GARCEZ; SCHLATTER, 2017; COSTA, 2018), são descritos eventos de formação em que duas professoras negociam a criação de uma unidade didática e a apresentação dos materiais em um evento acadêmico. Ao construir a identidade de professoras-autoras-formadoras, as participantes constituíram um repertório de trajetórias paradigmáticas (WENGER, 1998) a partir da investigação de suas práticas pedagógicas e do estabelecimento de parcerias em coautoria, atividades que constituem letramentos acadêmico-profissionais valorizados nas comunidades de prática em que participam.

Palavras-chave: Formação de Professores; Autoria; Identidade profissional.

Title: Dialogue with peers in professional training and the construction of the identity of the teacherauthor-educator

Abstract: This paper analyzes the construction of the teacher-author-educator identity in an academic context of induction to teaching practice, to continuous reflection on the practices and to written reports on pedagogical activities aiming at promoting dialogue and knowledge-sharing with their peers and the wider professional community. Based on a perspective of teacher's education as a social practice emerging from the interactions between teachers (NÓVOA, 1995; PÉREZ-GÓMEZ, 1995; GARCEZ; SCHLATTER, 2017; COSTA, 2018), teacher's education events are described in which two teachers negotiate the design of a lesson plan and the presentation of the materials in an academic conference. While constructing the identity of teacher-author-educator, the participants built a repertoire of paradigmatic trajectories (WENGER, 1998) by investigating their pedagogical practices and

\footnotetext{
${ }^{1}$ Doutor em Letras pela Universidade Federal do Rio Grande do Sul; Professor de Espanhol e Português na Framingham State University. Orcid: https://orcid.org/0000-0003-4377-763X

E-mail: evargasdacosta@framingham.edu

${ }^{2}$ Doutora em Letras pela Pontifícia Universidade Católica do Rio Grande do Sul; Professora no Curso de Licenciatura em Letras e no Programa de Pós-Graduação em Letras, Universidade Federal do Rio Grande do Sul. Orcid: https://orcid.org/0000-0003-4718-0574

E-mail: margarete.schlatter@gmail.com
} 
establishing co-authoring partnerships, activities that are part of academic-professional literacies valued in the communities of practice in which they participate.

Keywords: Teacher education; Authorship; Professional identity.

\section{Introdução}

A formação profissional dos professores e os conhecimentos produzidos por eles acontecem prioritariamente no e a partir do cotidiano de sua prática (NÓVOA, 1995; 2007). Essa premissa sustenta e é sustentada neste trabalho ao descrevermos a construção da identidade do professor-autor-formador. Este artigo apresenta um recorte de uma pesquisa etnográfica que investigou como acontece a formação de professores em um programa de português como língua adicional no âmbito de um curso de Letras em uma universidade

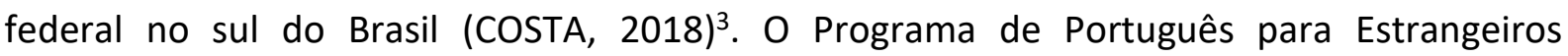
(doravante PPE), cenário desta pesquisa, é um programa de extensão que tem como objetivos promover a formação de professores de português como língua adicional (PLA) e contribuir para a expansão e o aprimoramento do ensino e da pesquisa. Analisamos aqui as trajetórias de participação de duas professoras em eventos de formação, definidos por Costa (2013) como momentos propícios para aprender a ensinar. A lente etnográfica dos eventos de formação oferece uma ferramenta de análise para as interações entre professores em diferentes contextos de atuação e de práticas de letramentos acadêmico-profissionais, que incluem, por exemplo, estágios de formação, atividades de planejamento, prática de ensino, participação em seminários e eventos acadêmicos. Entendendo que é nas práticas do dia a dia que os professores constroem sua formação (NÓVOA, 1995; PÉREZ GÓMES, 1995), atuando como profissionais reflexivos (SCHÖN, 1983; 2000), um evento de formação caracteriza-se por interações entre professores envolvendo ações, tópicos, propósitos e resultados relacionados a fazer ensinar e à construção de conhecimentos teórico-práticos e de identidades profissionais.

Nas interações com seus pares mais e menos experientes, os professores do cenário analisado constroem primordialmente a identidade de professor-autor, um professor que se engaja em interações com os colegas para narrar suas experiências e justificar suas escolhas e ações pedagógicas (GARCEZ; SCHLATTER, 2017). Dentre as modalidades de formação identificadas por Costa (2018), encontram-se: a) o seminário de formação, conduzido por uma coordenadora pedagógica e organizado a partir de perguntas exploratórias de modo a proporcionar aos participantes oportunidades de relatarem e analisarem reflexivamente sua prática; b) tutorias, em que um participante menos experiente é assistido por outro mais experiente na preparação de planos de aula, elaboração de instrumentos de avaliação e desenvolvimento de projetos pedagógicos; d) docência compartilhada, em que duas

\footnotetext{
${ }^{3}$ A pesquisa de Costa (2018) obteve aprovação no Comitê de Ética em Pesquisa da Universidade Federal do Rio Grande do Sul (Parecer n 1.173.553; Data da Relatoria: 30/07/2015).
} 
professoras ministram aulas conjuntamente, preparam e executam planos de ensino e projetos pedagógicos e, eventualmente, precisam resolver problemas emergentes da interação com os alunos em sala de aula; d) a sala dos professores, como espaço de encontros não programados que apresentam potencial de aprendizagem para os professores sobre elementos da cultura local onde trabalham, além de ser um espaço fértil para a ajuda mútua e o estabelecimento de parcerias. Essas modalidades oferecem aos professores oportunidade de narrar experiências e justificar suas escolhas em um movimento de reflexão conjunta, isto é, no contexto de atuação desses professores, a presença de outro colega é um convite a refletir conjuntamente.

Para além da identidade de professor-autor, Costa (2018) identificou que alguns participantes avançam a construção de sua autoria como professores, entendida como a construção da própria singularidade nas atividades em que participam, e passam a construir a identidade de formadores. No presente trabalho nos dedicamos a discutir a identidade emergente de professor-autor-formador (GARCEZ; SCHLATTER, 2017) com base em interações entre duas participantes. Essas participantes, professoras-bolsistas do programa investigado e ambas pós-graduandas em Letras, projetam trajetórias de professor-autor-formador ao se engajarem na discussão e no registro de suas reflexões sobre materiais didáticos e na produção de um trabalho para apresentar em um congresso acadêmico. Os dados mostram que as participantes atuam em um espaço pautado pelo incentivo e valorização da interlocução com o outro e da construção de (co)autoria, em que empreendimentos comuns são construídos conjuntamente em práticas não finitas, sendo as possibilidades de identidades abertas e fluidas.

No intuito de descrever o cenário onde as participantes observadas trabalham, apresentamos a seguir uma síntese sobre o que é o PPE. A seguir, aprofundamos o conceito de formação que embasa o programa. Nas seções "O exercício da autoria como formação de professores no PPE" e "A construção da identidade de professora-autora-formadora", respectivamente, apresentamos a metodologia de pesquisa e a análise dos dados e, por último, ressaltamos a importância de uma perspectiva local e situada para a compreensão das identidades construídas.

\section{O PPE: ensino, pesquisa e formação}

O PPE, cenário desta pesquisa, é um programa de extensão que tem como objetivos promover a formação de professores de português como língua adicional (PLA) integrando prática de ensino, reflexão continuada e pesquisa sobre o fazer ensinar. Há três linhas principais que norteiam as atividades do programa: a) constituir-se como um centro de formação continuada de professores de PLA; b) expandir e aprimorar o ensino de PLA, relacionando inovações em práticas de ensino com formação continuada; e c) desenvolver 
pesquisas na área. Desse modo, formação, ensino e pesquisa constituem-se como três pilares. Em mais de 20 de anos de trajetória, o PPE, além de funcionar como plataforma de articulação de políticas de internacionalização da universidade, atendendo a estudantes estrangeiros e residentes em Porto Alegre e região metropolitana, tem sido um importante espaço de desenvolvimento de pesquisas sobre a área de PLA, com considerável produção de trabalhos de conclusão de curso, dissertações de mestrado e teses de doutorado, além de artigos acadêmicos e simpósios sobre a área (SCHLATTER; GARCEZ, 2018).

O eixo da formação dos professores é voltado a graduandos, mestrandos e doutorandos da faculdade de Letras que atuam como professores-bolsistas nos diversos cursos oferecidos e a outros estudantes interessados em iniciar-se na docência em PLA no PPE. A formação acontece na prática de ensino e na discussão de visões teóricas durante seções de seminário, docência compartilhada, tutorias e outras oportunidades para a colaboração e ajuda mútua. Práticas de formação, incluindo a prática de ensinar, em seu caráter experimental, são privilegiadas e alimentam pesquisas, apontando para práticas de produção de conhecimento informadas pelas práticas de sala de aula. Formação de professores, ensino presencial e a distância, português para falantes de línguas próximas e distantes, concepção de cursos, currículo, ensino de literatura, cultura e de aspectos linguístico-discursivos, elaboração de materiais didáticos e práticas de avaliação compõem o espectro de temáticas abordadas pelos trabalhos de pesquisa realizados no âmbito do programa ${ }^{4}$.

O Instituto de Letras, que abriga o programa, oferece cursos de Licenciatura e Bacharelado em Letras, com disciplinas nos eixos de língua, linguística, literatura e teoria literária, formando professores de língua portuguesa, línguas adicionais e tradutores. No PPE, há uma série de cursos de língua, literatura e cultura voltados para jovens e adultos estrangeiros (com ou sem vínculo com a universidade), nos quais o professor-bolsista (estudante de graduação ou pós-graduação em Letras) constitui uma experiência profissional e uma experiência de aprendizagem. Embora não exista uma licenciatura específica em PLA na instituição, a formação acontece no PPE, nas modalidades expostas na introdução deste artigo, e nos diferentes cursos de Licenciatura, por meio de ofertas semestrais de disciplinas de programas para o ensino e estágio supervisionado em PLA.

A combinação de uma série de convênios gera a necessidade de criar cursos que atendam a diferentes expectativas dos alunos e das instituições parceiras. Além disso, os interesses dos professores, com suas próprias histórias e motivações para pesquisar, são incentivados e geram a concepção de novos cursos. Um curso, por exemplo, pode corresponder a um projeto específico de pesquisa ou compor um eixo de aprendizagem elementar de língua, guiado por pequenos projetos de aprendizagem (KRAEMER, 2012). Alguns dos cursos oferecidos pelo PPE são Português Básico, Intermediário e Avançado,

\footnotetext{
${ }^{4}$ Para uma lista dos trabalhos realizados no PPE, consultar Costa (2018).
} 
Conversação, Leitura e Produção Textual, Contos e Crônicas, Literatura Brasileira, Prática Teatral, História e Cultura Gaúcha, Canção Brasileira, Preparatório para o Certificado de Proficiência em Língua Portuguesa para Estrangeiros (Celpe-Bras), entre outros, e uma modalidade de curso online 5 . O programa conta com um jornal impresso e online que funciona como plataforma de publicação de textos de alunos e uma coluna para professores e com a Feira Cultural, um evento semestral, organizado e gerenciado pelos professores, no qual os alunos realizam apresentações de projetos desenvolvidos em suas aulas, gerando uma possibilidade de interlocução real dos trabalhos desenvolvidos com a comunidade do Instituto de Letras.

As discussões sobre a prática de ensino nos seminários de formação, que reúnem professores mais e menos experiente, a indução à prática de ensino supervisionada, o tutoramento dos professores-bolsistas do curso de graduação em Letras pelos professores mais antigos no programa, e o desenvolvimento de pesquisas nos níveis de graduação e pósgraduação, concentradas nas áreas de ensino e aprendizagem de PLA, elaboração de materiais didáticos e avaliação de proficiência, são ações constantes no âmbito do programa, o que o torna, por seus próprios objetivos, um relevante laboratório de formação de professores (SCHLATTER; GARCEZ, 2018).

\section{O exercício da autoria como formação de professores no PPE}

Para Zeichner (2010), o paradigma segundo o qual a universidade e o conhecimento acadêmico são as únicas fontes autorizadas sobre como se ensina precisa ser superado, por meio da adoção de uma relação não hierárquica entre os saberes dos acadêmicos, dos profissionais e das comunidades. Somente um trabalho coordenado entre a universidade e o lócus profissional pode expandir as oportunidades de aprendizagem sobre o ensino para futuros professores e melhor prepará-los para o início da prática docente. Esse tipo de formação híbrida funciona como um continuum em que ações de indução são uma via para operacionalizar efetivamente a transição da etapa de formação inicial e continuada (ZEICHNER, 2010; KORHONEN ET AL., 2017), conforme ocorre no PPE. Tal hibridismo produz indução ao trabalho docente por meio de uma série de experiências de trabalho colaborativo (COSTA; SCHLATTER, 2017; COSTA, 2018) que passamos a detalhar a partir de agora.

Como vimos, o eixo central do PPE está nos seminários de formação de professores, na indução à prática pedagógica, e nas práticas de tutoria de professores mais experientes com os novatos. Para Schlatter (2008), é preciso diminuir a distância entre teoria e prática na formação de professores de línguas, e isso é possível com uma abordagem de formação que

\footnotetext{
${ }^{5}$ Ver, por exemplo, Fornari (2006), sobre Contos e Crônicas; Conceição (2011), sobre Prática Teatral; Souza (2014), sobre Canção Brasileira; Bulla (2014), sobre cursos online.
} 
inicie pela análise conjunta das concepções dos professores mais e menos experientes quanto a saber uma língua, aprender e ensinar uma língua, materiais didáticos e instrumentos de avaliação. Além disso,

[...] baseadas nas suas próprias teorias e experiências [...] e o contexto social da sala de aula, o segundo conjunto de perguntas que considero fundamental discutir com os (futuros) professores é: O que significa ser um bom aluno e um bom professor? $\mathrm{O}$ que significa ser um aluno ou professor ruim? O que é uma aula boa ou ruim? O que é um material bom ou ruim? O que é uma avaliação justa ou injusta? A partir dessas perguntas podemos ver quais são os conceitos que circulam entre os professores e tentar, a partir dessas noções, aos poucos, ir trabalhando outras visões interessantes, no intuito de refletir criticamente sobre o que estão fazendo e trazendo à discussão (SCHLATTER, 2008, p. 60).

A autora propõe também que os professores possam assumir maior protagonismo na compreensão do contexto de atuação por meio de questionamentos como: "Quem atua nesse contexto? Quais são as características desse contexto? Qual é o projeto político pedagógico? Quais são as práticas de ensino desenvolvidas? Como posso me inserir nesse contexto? $\mathrm{O}$ que podem ensinar os professores em exercício?" (COSTA, 2008, p. 61). A compreensão dos contextos é fundamental na formação dos professores no PPE e serve de propósito e meio para compreender as teorias sobre ensino e aprendizagem valorizadas em diferentes locais de atuação profissional ${ }^{6}$.

A proposta une, portanto, a valorização das experiências individuais com a sensibilização para os contextos de ensino, o que confere, de acordo com a perspectiva adotada em Costa (2018) e neste artigo, uma ação de formação orientada pelo dialogismo entre indivíduos e seus contextos. Um traço ainda mais destacado dessa relação é a composição do corpo docente do programa: doutorandos, mestrandos e graduandos. Num ambiente em que todos se assumem em formação, pesquisas de mestrado e doutorado são motivadas pelas discussões, pelas observações e pelas participações em um seminário semanal em que todos se reúnem, gerando um espaço de trocas entre diferentes níveis de experiências e repertórios de conhecimentos. Assim, a formação de professores é uma ação coletiva baseada em conversas, diálogos e colaboração, elementos possibilitadores de reflexões que podem gerar impacto na formação. A troca de experiências e o dirimir de dúvidas são realizados de modo exploratório, em constante diálogo, o que rapidamente se torna natural para os novos participantes do programa de formação do PPE (COSTA, 2018). Essas atividades são constitutivas da atuação acadêmica-profissional dos participantes,

\footnotetext{
${ }^{6}$ A necessidade da compreensão do contexto de atuação para participar dele de modo mais crítico e criativo no intuito de promover aprendizagem está tratada de modo mais detalhado em Schlatter e Garcez (2012, p. 43 a 48), em seção denominada "Observar para entender e planejar".
} 
caracterizando-se, como veremos mais adiante, em letramentos acadêmicos que possibilitam a participação como professor-autor e professor-autor-formador.

A troca de experiências entre menos e mais experientes tem sido pressuposto em vários programas de formação de PLA nos contextos universitários brasileiros. O trabalho coletivo, unindo no mesmo espaço graduandos e pós-graduandos, parece ser uma forma que coordenadores e desenvolvedores de programas encontraram de envidar os "laboratórios de formação", com a presença constante dos encontros para discussões de teorias (SCHLATTER, 2008; SILVA; LEURQUIN, 2014). Tais encontros podem ser considerados como pontos de articulação entre teoria e prática, ou de concretização das reflexões. Seja em reuniões ou em encontros informais em convergência, experiências passadas são potencializadas em transformações futuras, criando espaços de trabalho coletivo e colaborativo.

Entendemos, portanto, que formação é uma aprendizagem contínua e situada, sendo os ambientes de trabalho primordiais em tais processos, individual ou coletivamente, o que faz da formação "uma construção humana e social, na qual, os diferentes intervenientes possuem margens de autonomia na condução dos seus projetos próprios" (NóVOA, 1995, p. 30). A formação é um percurso histórico de instauração de dispositivos de parceria entre todos os atores sociais, profissionais e institucionais, promovendo as comunidades de prática (WENGER, 1998) e espaços híbridos e coletivos de trabalho como instrumentos de formação (NÓVOA, 2007).

Essa visão coloca o professor como protagonista das ações desempenhadas e abre um espaço para a construção de narrativas sobre o próprio trabalho, em que a prática é o fator de maior relevo, enquanto a teoria é introduzida como modo de organizar tais narrativas. Em um cenário em que se tem como objetivo integrar atividades pedagógicas e acadêmicas, a relação teoria e prática torna-se ponto fundamental para a construção da autoria profissional. Assim, observamos que no PPE desenvolve-se um conjunto de práticas que convergem para o desenvolvimento da identidade de um professor-autor (GARCEZ; SCHLATTER, 2017). Concebida como aspecto central da formação de professores, Garcez e Schlatter (2017) entendem autoria como a construção da própria singularidade nas atividades em que se participa, e formulam o que consideram conhecimentos necessários para o desenvolvimento da autoria docente:

[...] a autoria se materializa na tomada de posições públicas, expressas na interlocução entre pares e refletidas na prática com os educandos, acerca de princípios e métodos de ensino, e critérios e procedimentos de avaliação. A autoria se manifesta também, de modo talvez ainda mais evidente, na produção e apreciação compartilhada de materiais e instrumentos de ensino e de avaliação da aprendizagem. E a autoria também se manifesta [...] no relato sistemático de práticas pedagógicas vividas, de tomadas de decisão coletivas e de ações de enfrentamento dos diversos desafios do fazer ensinar e do fazer aprender. (GARCEZ; SCHLATTER, 2017, p. 18). 
Os autores afirmam que interlocuções pedagógicas bem-sucedidas estão relacionadas com a construção de singularidades e responsabilidades mediante a tarefa de explicitar o que está sendo feito do modo como está sendo feito. Para que a autoria seja possível, não é necessário consenso ou unanimidade, mas é imprescindível o diálogo respeitoso e a apresentação fundamentada do que se faz. Garcez e Schlatter (2017) propõem que as licenciaturas possibilitem o desenvolvimento do professor-autor e do professor-autorformador. O primeiro significa investir na autoria do docente tanto em decisões em nível das diretivas educacionais quanto das próprias demandas da sala de aula e de outros contextos de ensino. A linha estruturante para a formação do professor-autor está na articulação de conhecimentos a) para a resolução de problemas emergentes da prática; b) na convivência entre professores mais e menos experientes; e c) pela produção de reflexões sobre o que significa aprender a ensinar em um contexto específico. Para os autores, é articulando o problema a ser enfrentado, ao "estudar, trocar ideias, propor projetos, elaborar materiais, divergir, buscar ajuda, experimentar, avaliar e refletir sobre o que fizeram" (p. 25), que os participantes constroem a sua singularidade e a responsabilidade pela singularidade produzida. Adicionalmente, os autores advogam pela formação do professor-autor-formador, que tem a ver com promover oportunidades para o registro do repertório construído, assumindo, para além da identidade de professor-autor, a identidade de um professor que, ao produzir textos, se responsabiliza pelos próprios repertórios e impacta a formação de outros professores. Em termos práticos, é importante a promoção de oportunidades de encontros entre professores para a manifestação de suas produções autorais e para o registro das experiências nos cenários onde atuam, pautando o protagonismo dos professores.

Para mostrar etnograficamente como a formação pode ser vista como um projeto de construção coletiva e situada no tempo e no espaço de atuação dos professores, passamos a descrever, na próxima seção, as abordagens metodológicas do presente trabalho e a etapas de geração e análise dos dados. Na seção seguinte, discutimos como a construção das identidades profissionais acontece nas negociações entre pares sobre os sentidos atribuídos ao que estão fazendo e como podem registrar essas práticas em uma participação valorizada no contexto acadêmico do qual fazem parte.

\section{Uma pesquisa etnográfica sobre formação de professores}

A pesquisa extensiva que gerou os dados apresentados neste trabalho foi realizada em 2015, e dela participaram nove professores selecionados por estarem participando em ação de tutoria, docência compartilhada, dando aulas regulares no programa, estarem em diferentes estágios de formação e frequentando os seminários de formação. O grupo de professores foi acompanhado em interações entre si, especialmente na sala do PPE, e, 
eventualmente, em interações com a equipe coordenadora, composta por três professoras do Instituto de Letras, as quais foram igualmente convidadas a participar da pesquisa. Os doze participantes, professores e coordenadoras, indicaram seu aceite por meio de termo de consentimento livre e esclarecido seguindo as orientações do Comitê de Ética em Pesquisa da universidade onde a pesquisa foi realizada (Resolução 466/12).

Durante a pesquisa de campo, o pesquisador, um dos autores deste texto, circulou por diferentes espaços do Instituto de Letras, e visitou outras universidades acompanhando os participantes em atividades relacionadas ao PPE como um observador participante. No presente trabalho, nos dedicaremos a analisar primordialmente o trabalho em parceria entre as professoras Julia e Beatriz (pseudônimos), duas pós-graduandas que aproveitam a modalidade de docência compartilhada para ampliar suas identidades como produtoras de conhecimento que podem impactar a prática de professores do programa em audiências externas. Júlia, no período de geração dos dados, era mestranda em Linguística Aplicada, e ensinava no PPE desde 2011. A participante já havia publicado artigos com colegas sobre cursos que ensinou no programa. Seu trabalho de conclusão de curso trata do ensino de PLA por projetos pedagógicos. Beatriz, por sua vez, era doutoranda em Teoria Literária, atuava como professora do PPE desde 2013. Sua pesquisa de doutorado enfocou-se no estudo da palavra como performance e era um membro ativo em grupos de pesquisa sobre literatura em outras universidades. No semestre em que a pesquisa de campo foi realizada, Júlia e Beatriz estavam trabalhando em docência compartilhada no curso de Práticas do Discurso Oral $^{7}$, oferecido pelo PPE para estudantes estrangeiros de nível intermediário superior e avançado. É a partir das interações para preparação de aulas para esse curso que Beatriz convida Júlia para a discussão de uma unidade didática para o curso de Literatura Brasileira II que está ensinando.

Os dados de interação entre as duas participantes que apresentamos a seguir foram gerados por meio de observação participante, tomando notas de campo e gravações em áudio das interações entre as professoras. Das notas e áudios, foram produzidos diários de campo e transcrições de interações que posteriormente foram tratados e segmentados pela ótica dos eventos de formação, privilegiando a perspectiva êmica (MASON, 1996), analisando as ações dos professores em eventos de formação por meio dos princípios da pesquisa etnográfica (FONSECA, 1999) como estranhamento, comparação e reflexividade. Como anunciado na introdução, um evento de formação é uma interação entre professores caracterizada por ações, tópicos, propósitos e resultados relacionados a fazer ensinar e à construção de conhecimentos e de identidades profissionais. Para Costa (2013), em interações entre professores é possível identificar um evento de formação quando

\footnotetext{
${ }^{7}$ Para uma discussão aprofundada sobre os efeitos da modalidade de docência compartilhada para a formação dos professores do PPE, ver Costa (2018).
} 
[...] os participantes tratam de tópicos sobre a sala de aula e se engajam em ações conjuntas tais como apresentar modelos e estratégias de ensino, relatar situações vividas em sala de aula, responder perguntas sobre questões de sala de aula e oferecer ajuda quando solicitada. As narrativas com base em interpretações de suas experiências são um recurso reconhecido pelos participantes como constitutivo dos eventos de formação e, além disso, os conhecimentos técnicos e práticos se entrelaçam, o que torna o evento de formação uma empreitada orientada por uma racionalidade técnico-prática (COSTA, 2013, p.139).

Costa (2018) analisou um conjunto de 15 eventos de formação ${ }^{8}$ em que dois ou mais participantes interagem face a face, e, pela caracterização das ações, tópicos e propósitos da interação, depreendeu-se que o empreendimento comum dos participantes tem relação com aprender a ser professor daquele local específico onde atuam, confirmando a proposição de Costa (2013). No entanto, observou-se que, nos eventos gerados, os eventuais resultados da interação também se tornam relevantes. Ações como relatar uma experiência para prover ajuda a pedidos de colegas caracterizam esses encontros como momentos de reflexões conjuntas. Os propósitos de tais ações normalmente se relacionam à elaboração de planos de aula e à apresentação de tais planejamentos, seja como ajuda ou oferta de ajuda. Os tópicos mais recorrentes são planejamento de aula, materiais didáticos, tarefas e projetos pedagógicos. $E$, como resultados, observou-se a prevalência de apresentações e execuções de planos de aula e a negociação de acordos que levaram a entendimentos comuns sobre as aulas. Todas as ações observadas em Costa (2018) apontam em diferentes medidas para dimensões de formação do professor-autor e do professor-autor-formador, o que possibilitou avançar na descrição de um evento de formação como um momento propício para aprender a ensinar e como espaço de construção de uma identidade docente em um determinado local. A seguir, descrevemos as instâncias de interação entre Julia e Beatriz e analisamos a construção de suas identidades como professoras-autoras-formadoras.

\section{A construção da identidade de professora-autora-formadora}

Para Garcez e Schlatter (2017), ser professor-autor-formador tem a ver com evoluir na sua prática enquanto se produz formação para os colegas. Para eles, registrar as experiências que façam bom sentido educacional, por meio de produções escritas com vistas à publicação, resulta em acúmulo de experiência sobre a prática e insere o professor nas discussões sobre a profissão docente. $\mathrm{O}$ que se observa no PPE não quer dizer que haja a obrigatoriedade ou a

\footnotetext{
${ }^{8} \mathrm{Um}$ total de 61 eventos de formação foram reunidos durante a etapa de segmentação dos dados e segmentados pela natureza das ações, propósitos, tópicos e resultados da interação. Os dados foram primeiramente organizados de acordo com as modalidades de formação em que ocorreram: seminários, tutorias, docência compartilhada ou em encontros informais na sala dos professores.
} 
exigência de que os professores produzam artigos ou relatos escritos de suas práticas. As demandas com as quais eles lidam são muitas: aulas de graduação e pós-graduação, os cursos que ensinam no PPE, reuniões e seminários. Nessas atividades, assumir a identidade de professor-autor é fundamental para participar. No entanto, para alguns professores, a formação como professor-autor-formador é um desejo e um projeto pessoal de desenvolvimento profissional, produzido localmente em parcerias com colegas que possuem objetivos análogos. Essas parcerias facilitam o empreendimento de tornar-se, além de professor-autor de sua própria prática, um professor-autor-formador que, por meio de registros das singularidades de seu trabalho, estabelece interlocuções com os professores locais e com uma audiência mais ampla - professores e pesquisadores da área de PLA e de ensino de línguas em geral -, caracterizando, desse modo, também uma participação em práticas letradas valorizadas nesse meio.

Os dados que passamos a descrever e analisar tratam-se de segmentos de uma conversa entre Beatriz e Júlia durante uma reunião entre as duas participantes, na qual elaboram questões para uma unidade didática (UD) para o curso de Literatura Brasileira II, ministrado por Beatriz. O objetivo da UD é fomentar uma reflexão guiada aos alunos sobre a leitura do romance "Graduado em Marginalidade" ${ }^{9}$, de Sacolinha, e as questões levantadas pelas professoras giram em torno de variação linguística, escolhas do autor e o papel do professor. Concomitantemente, as professoras preparam uma apresentação para um congresso sobre ensino e aprendizagem de línguas adicionais que se realizou no mesmo ano da geração de dados em uma universidade próxima àquela onde o evento foi observado.

Júlia e Beatriz almoçam em um restaurante no campus universitário e preparam-se para a reunião que terão em seguida. Durante o almoço, Beatriz contextualiza o trabalho que tem feito em aula, relatando a Júlia as etapas da aula e as respostas dos alunos, majoritariamente estudantes chineses que participam de um convênio com a universidade, fornecendo um olhar para o que foi planejado e para os resultados alcançados. Quando as professoras terminam de almoçar, caminham para o pátio do campus. O Excerto 1 mostra como as participantes elaboram uma seção do material intitulada "De Olho na Língua" e problematizam questões relativas à estrutura da UD, analisando a ideia de trabalhar com a leitura do livro por capítulos e ponderando sobre o tipo de questões que vão elaborar para guiar a discussão a partir dos pontos de vista dos alunos.

\footnotetext{
${ }^{9}$ O romance "Graduado em Marginalidade", de Sacolinha (pseudônimo de Ademiro Alves de Sousa), foi publicado pela editora Confraria do Vento em 2009. O romance é narrado pelo protagonista que perde sucessivamente pai, mãe e amigos para o crime e para a corrupção policial. Recusando-se a sucumbir ao rancor que tais perdas pressupõem, a passagem pela prisão desencadeia a ira do narrador, que decide, então, buscar vingança.
} 


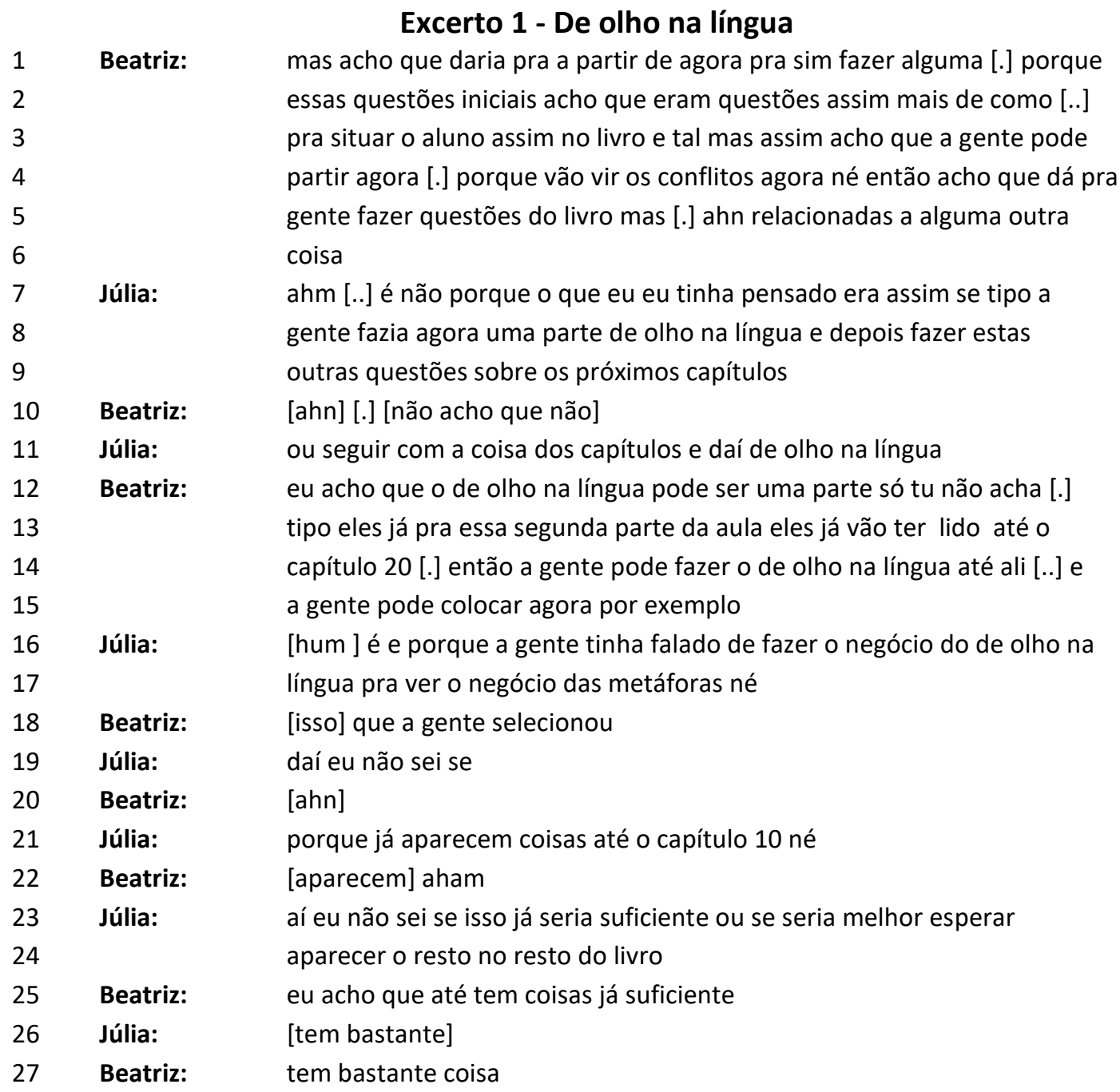

(Diário 3, 03/06/15, notas de campo, gravação em áudio, fotografias)

Nesse novo enquadramento, após a contextualização, as professoras precisam definir por onde começar o trabalho mais específico com a UD. Beatriz crê que precisam tratar de questões referentes ao enredo da obra, enquanto Júlia propõe um trabalho mais focado em questões linguísticas intercaladas com o estudo do enredo propriamente (linhas 1-10). No sentido de negociar o que é prioritário para a UD na etapa inicial do encontro, elas precisam resolver se os capítulos que os alunos já leram do romance "Graduado em Marginalidade", no ponto do curso em que estão, são suficientes para elaborar questões referentes a temas linguísticos (linhas 21 a 27). Ambas concordam que sim. Ambas reconhecem que há diferentes pontos de vista em jogo e que o trabalho precisa ser planejado com os acordos estabelecidos. Além disso, elas precisam afinar pontos de vista que, ao trazerem para conversa, parecem já ter passado por algum tipo de elaboração. As professoras constituem-se como professorasautoras nesse encontro, à medida que precisam justificar, pela singularidade do que produzem, suas ações e proposições uma para a outra: Júlia trazendo sua leitura da obra, e Beatriz, além da sua leitura, informando sobre o andamento da aula. 
Para Schlatter e Garcez (2018), o professor-autor "justifica suas escolhas, o modo como se apropria de materiais didáticos e os adapta a cada novo uso, de acordo com a sua experiência, as suas convicções, as necessidades dos alunos e as expectativas em cada tempo e espaço escolar" (p. 13). A abertura do evento mostra um espaço de retomadas dos acordos previamente estabelecidos (linha 16) como um modo de justificar encaminhamentos, mas também a necessidade de abertura para mudanças contingentes de acordo com novas reflexões (linhas 12-15, 25), com o propósito de que o trabalho a seguir seja possibilitado, atendendo a expectativas geradas pelo que ocorre na sala de aula. Chegar a acordos parece significar uma conquista para o trabalho colaborativo que as professoras buscam estabelecer no início da reunião.

O Excerto 2, a seguir, mostra as professoras engajadas em uma negociação que aponta para entendimentos co-construídos sobre uma UD como um conjunto de ações que possam promover o estudo da obra de Sacolinha. Para as professoras, uma questão saliente na obra é a variação linguística, mas elas precisam negociar diferentes entendimentos para chegar a um acordo sobre como operacionalizar a materialidade linguística apresentada no livro em questões que despertem a reflexão dos alunos para questões sociais no Brasil.

\begin{tabular}{|c|c|}
\hline Júlia: & não sei [.] isso não tem como se justificar né [.] essa essa ((inaudível)) \\
\hline Beatriz: & porque esses dois falam assim e os outros não [...] \\
\hline Júlia: & $\begin{array}{l}\text { não é só porque é pobre porque ali todo mundo é [.] não tem como se } \\
\text { justificar }\end{array}$ \\
\hline Beatriz: & $\begin{array}{l}\text { ou ou que eu quis dizer assim Júlia que ou porque não tem educação } \\
\text { mas todos ali em alguma medida têm uma educação restrita, me parece }\end{array}$ \\
\hline Júlia: & [sim] \\
\hline Beatriz: & então por que será que esses dois [..] agora eu fiquei me perguntando \\
\hline Júlia: & eu também fiquei me perguntando \\
\hline Júlia: & $\begin{array}{l}\text { é que às vezes eu fiquei pensando será que foi uma coisa de } \\
\text { momento e que ele fez e esqueceu de fazer nos outros personagens } \\
\text { ((ri)) ou ele assim fez só na hora que deu vontade e depois ele perdeu } \\
\text { a vontade de marcar }\end{array}$ \\
\hline Beatriz: & [tá mas agora uma] pergunta bem pergunta assim \\
\hline Júlia: & do autor assim \\
\hline Beatriz: & $\begin{array}{l}\text { o [.] esse nóis cunversa tá tudo bem [.] tá relacionado a talvez a [.] a um } \\
\text { lugar de sei lá de alguém que tem menos educação dessa formal mas a } \\
\text { gente também não usa isso nóis [.] eu fiquei pensando agora [.] isso } \\
\text { necessariamente é desse lugar ((perguntando)) }\end{array}$ \\
\hline Júlia: & $\begin{array}{l}\text { não aí é que tá [.] o que pode existir com alguns casos de variação é } \\
\text { justamente anh [...] tem coisas que são vistas com estigma mas que } \\
\text { nós mesmos fazemos [..] }\end{array}$ \\
\hline Beatriz: & [aaah] \\
\hline Júlia: & $\begin{array}{l}\text { entende [..] mas a gente não percebe que faz entende [.] ou a gente não } \\
\text { aceita que faz }\end{array}$ \\
\hline & aham[.] ah tá \\
\hline
\end{tabular}




\begin{tabular}{|c|c|c|}
\hline 27 & Júlia: & por exemplo o mesmo com a gente vamos lá a gente \\
\hline 28 & Beatriz: & aham \\
\hline 29 & Júlia: & a gente pode tranquilamente conhecer pessoas que \\
\hline 30 & Beatriz: & utilizam isso \\
\hline 31 & Júlia: & [que enfim] que têm \\
\hline 32 & Beatriz: & aham \\
\hline 33 & Júlia: & uma escolaridade maior [.] mas elas não vão se dar conta disso elas não \\
\hline 34 & & vão aceitar \\
\hline 35 & Beatriz: & [então] aí é legal até [..] isso do estigma é legal \\
\hline 36 & Júlia: & [isso do] ((inaudível)) que não tem \\
\hline 37 & Beatriz: & tu não acha que estigma é legal \\
\hline 38 & Júlia: & ((olha para Beatriz, pensa)) [..] não sim mas no caso do nóis \\
\hline 39 & Beatriz: & ahn \\
\hline 40 & Júlia: & aann [..] eu não sei [.] na verdade eu não sei \\
\hline 41 & Beatriz: & ahm como assim não sabe Júlia [.] o que tu tá pensando \\
\hline 42 & Júlia: & não [.] é que eu não sei se o nóis vai ser falado por [..] não eu acho \\
\hline 43 & & que sim acho que vai ter pessoas com maior escolaridade e com mais \\
\hline 44 & & formação [.] que eu sei que vão falar nóis por algum motivo assim [.] \\
\hline 45 & & pra marcar ou identidade ou sei lá entende \\
\hline 46 & Beatriz: & $\operatorname{sim}$ \\
\hline 47 & Júlia: & assim [..] tu não precisa ser pobre pra falar nóis \\
\hline 48 & Beatriz: & [pra falar nóis] \\
\hline 49 & Júlia: & outra coisa que eu pensei talvez esteja ligado a estereótipo mas eu pensei \\
\hline 50 & & assim do pessoal ligado a hip-hop sei lá \\
\hline 51 & Beatriz: & isso aham tipo \\
\hline 52 & Júlia: & porque tem pessoas que tem formação que tem escolaridade mas \\
\hline 53 & & estão ligadas a um grupo que tem suas identidades assim \\
\hline 54 & Beatriz: & [eu tava] pensando também [.] a gente tá tudo \\
\hline 55 & & nervoso a gente tá tudo aqui [..] eu posso dizer né ((olha fixo para Júlia)) \\
\hline 56 & & eu posso \\
\hline 57 & Júlia: & [sim] \\
\hline 58 & Beatriz: & pode aparecer isso \\
\hline 59 & Júlia; & sim com certeza \\
\hline 60 & Beatriz: & a gente tá tudo aqui reunido \\
\hline 61 & Júlia: & só que aí ahn hum mas aí justamente vai [.] tá ligado a essa \\
\hline 62 & & identidade a gente vai reconhecer isso, ligado a essa identidade vai nos \\
\hline 63 & & parecer mais natural aí no caso \\
\hline 64 & Beatriz. & sim mais direta a relação aham \\
\hline 65 & Júlia: & daí só que aqui a primeira coisa que vai se pensar ai é é é \\
\hline 66 & Beatriz: & ((suspira forte)) será que não é [..] depende do que a gente for \\
\hline 67 & & encontrar será que não daria pra encontrar [.] ahn algum registro de uma \\
\hline 68 & & pessoa com [.] porque a única coisa que eu não gostaria mesmo é tipo \\
\hline 69 & & porque assim falando sobre isso e tal pode pode \\
\hline 70 & Júlia: & não é porque [..] ah tá mas não sei se vai e também não sei se dá \\
\hline 71 & & [.] porque tem a entrevista do [..] \\
\hline 72 & Beatriz: & ahn \\
\hline 73 & Júlia: & ai o cara lá do do [.] do Vik Muniz \\
\hline 74 & Beatriz: & [qual cara] \\
\hline
\end{tabular}


Júlia:

Beatriz:

Júlia:

Beatriz:

Júlia:

Beatriz:

Júlia:

Beatriz:

Júlia:

Beatriz:

Júlia:

Beatriz:

Júlia:

Beatriz:

Júlia:

Beatriz:

Júlia:

Beatriz:

Júlia:

Beatriz:

Júlia:

Beatriz:

Júlia:

Beatriz:

Júlia:

Beatriz:

Júlia:

Beatriz:

Júlia:

Beatriz:

Júlia:

Beatriz:

Júlia:

Beatriz:
[.] ai o que se destacou mais começou a fazer eventos falar em eventos em todo o Brasil e trabalhava no lixão

[não] não sei

tá eu esqueci o nome do cara [.] mas como é o nome do documentário

[.] tu sabe o documentário

o Lixo Extraordinário

isso isso

aham aham

aí tem o cara lá que se destacou mais no vídeo e aí ele começou a trabalhar e a viajar pelo Brasil em eventos falando sobre reciclagem lalala ele meio que se tornou símbolo do negócio tá

e se não me engano tem uma entrevista dele mais quando ele começou isso uma entrevista dele no programa do Jô

aham

e que coisas

é

coisas de variação assim que [.] que assim eu acho que chama a atenção se não me engano.

aham

ele é um cara que não tem escolaridade mas que está numa posição super importante

aham isso é legal

ele foi colocado numa posição super importante de ser um porta-voz sei lá

tá [.] deixa eu anotar então

só que tem que [..] só que claro ele aquele caso de novo ele não teria

[.] ele é pobre

aham

e sem escolaridade mas

e será que de repente a gente encontraria [..] o oposto disso

ah eu tô procurando ((com mão fechada dá pequenos golpes na boca, pensando))

tá mas eu posso também tentar encontrar

((mão fechada na boca )) [...] tô tentando pensar em alguma pesquisa ((olha pra mim)) [...] da disciplina que eu fiz de Sociolinguística ahn

porque assim em alguma pesquisa teria os dados né

aham

se tivesse $[. .$.

((em tom bem baixo )) isso aí a gente encontra [...] ((riem)) ((começa a anotar)) peraí [.] estigma [..] lixo extraordinário [...] isso tem tudo a ver com o que eu falei naquela outra aula tipo que a pergunta poderia ser [...]

tá mas igual [...] bom igual poderia [...]

o que

não sei $[\ldots]$

o que Júlia 


$\begin{array}{lll}123 & \text { Júlia: } & \text { por que será que ele marcou esses dois [.] não vai ter como se } \\ 124 & & \text { justificar por ser pobre } \\ 125 & \text { Beatriz: } & \text { mas isso é bom ((interrompendo)) } \\ 126 & \text { Júlia: } & \text { sim sim por que mesmo que eles venham com essa resposta os outros } \\ 127 & & \text { também são } \\ 128 & \text { Beatriz: } & \text { [os outros] são } \\ 129 & \text { Júlia: } & \text { eles estão vivendo no mesmo contexto } \\ 130 & \text { Beatriz: } & \text { tá [.] acho bem bom }\end{array}$

(Diário 3, 03/06/15, notas de campo, gravação em áudio, fotografias)

As professoras trabalham em meio a muitas anotações em folhas avulsas nas páginas dos volumes de "Graduado em Marginalidade" que trazem em mãos enquanto conversam. Além disso, corrigem o material da UD à medida que vão renegociando novas possibilidades. Ao evoluir o encontro, elas passam a problematizar questões e a propor perspectivas e materiais que contribuam para a compreensão da obra e das temáticas emergentes identificadas. O longo trecho em que Júlia e Beatriz tentam entender o que significam certas escolhas do autor revela o quão importante é para ambas que haja um entendimento compartilhado entre elas para que possam elaborar questões a serem usadas em sala de aula. No Excerto 2, Júlia identifica um potencial problema de coerência nas escolhas do autor da obra analisada (linhas 1-13), o que ajuda Beatriz a construir um raciocínio sobre estigma e prestígio no português falado no Brasil frente aos usos escritos em falas em um romance que emula irregularmente tais variações (linhas 14-25), a partir de explicações que Júlia provê sobre o tema.

As professoras constroem identidades de professoras-autoras-formadoras a partir da articulação de um problema (linhas 1-65), seu enquadramento teórico e da respectiva proposição de modos de tratar o problema (linhas 66-130). Na concepção do problema, Júlia estabelece para Beatriz alguns elementos teóricos sobre como entender a variação linguística. As participantes concordam que a questão é complexa, e estereótipos do tipo "pobres falam com erros" não podem ser naturalizados, posicionamento defendido por Beatriz, que destaca que não quer reforçar estereótipos entre os estudantes (linhas 66-69). Júlia, ao longo da interação, vai se construindo como participante experiente em discussões teóricas sobre variação linguística e traz termos que servem aos anseios de Beatriz como "estigma", "identidades" e "prestígio" (linhas 35-38), inclusive fazendo referência à formação que teve em Sociolinguística (linha 110). As questões teóricas resultantes da identificação de uma problemática são acionadas para aprofundar a perspectiva de ensino que as professoras produzem singularmente, o que equivale à compreensão de que os aspectos teóricos não se sobrepõem às questões mais práticas, de fato, eles compõem a prática como reificações ${ }^{10} \mathrm{e}$

\footnotetext{
${ }^{10}$ As reificações referem-se aos modos de dar forma à experiência através da produção de objetos que solidificam tal experiência em coisificação (WENGER, 1998). Na dinâmica de participar nos engajamos, mas também projetamos discursos, conceitos, ou em nosso engajamento lançamos mão de objetos que materializam entendimentos dando-Ihes uma forma. Um exemplo disso pode ser a produção de
} 
emergem pelo modo como as ações vão sendo interpretadas. Para Garcez e Schlatter (2017), a formação dos professores-autores-formadores envolve uma troca de saberes diversos, os quais são mobilizados e (re) construídos situadamente com base em objetivos comuns, neste caso a elaboração de uma UD e sua apresentação em um congresso, contribuindo para as justificativas e tomadas de decisões. É a partir do aprofundamento da temática do estigma e prestígio atribuídos a certos usos linguísticos que as professoras visualizam modos de tratamento do problema.

Na segunda metade do Excerto 2 (linhas 66-130), Beatriz inicia a construção de uma proposta (a busca por outro texto que apresente as características de língua falada que desejam trabalhar com os alunos) para, ao mesmo tempo, destacar o que encontraram no livro e comparar com outros usos (linhas 66-69). A ideia de Beatriz é logo ratificada por Júlia como uma saída possível, e a inspira a lançar a ideia de um novo material específico que pode contribuir para a construção de um raciocínio sobre variação linguística e identidades sociais (linhas 73-104) com vistas a construir novas compreensões sobre os personagens no romance e também nas práticas sociais. Tudo é discutido com base na visão de que, se as questões problemáticas que vão identificando não forem esclarecidas e tratadas por elas, os alunos podem acabar reforçando estereótipos sobre pessoas pobres que não servirão para fazer um bom sentido da realidade, mas sim naturalizar preconceitos, em uma clara abordagem do ensino pela reflexão sobre justiça social. Essa reflexão poderá ser incorporada no relato que farão no congresso, evidenciando as experiências e particularidades que somente Beatriz e Júlia, enquanto professoras-autoras, viveram em local e tempo específicos (NÓVOA, 1995; 2007; SCHLATTER; GARCEZ, 2018).

Considerando os dados analisados nesta seção, pode-se apontar algumas características de eventos de formação em que professores-autores-formadores constroem identidades e relações. No caminho para a aprendizagem de se tornar um professor-autorformador, o colega funciona como um interlocutor com quem é preciso negociar, que precisa convencer e ser convencido. Nesse movimento transformam-se, por meio de reflexões conjuntas, seus próprios modos de ver o trabalho, bem como os pontos de vista do outro, que nessas instâncias atua como um coautor, isto é, um parceiro com quem se produz artefatos que façam bom sentido pedagógico e com quem se divide as responsabilidades pela singularidade construída na parceria. O trabalho de construção da coautoria das duas professoras passa pela contextualização das experiências de sala de aula, pelo reconhecimento de diferentes pontos de vista sobre como gerenciar o trabalho, pelo fechamento de acordos necessários para o tratamento dos materiais, temáticas e propostas. No centro dessa construção está o levantamento e a articulação de problematizações

materiais didáticos que incorporam e materializam construtos teóricos, repertórios de práticas compartilhadas entre seus desenvolvedores, e que oferecerão novos desafios de significação para os interlocutores dos materiais. 
relacionadas ao modo de tratar os materiais e os propósitos de sala de aula, o que exige a retomada e o fechamento de (novos) acordos e consensos.

Também é necessário negociar e renegociar diferentes entendimentos teóricos para problematizar o trabalho realizado e chegar a propostas concretas. O questionamento é preponderante e leva as professoras a constituírem uma afinação de discurso sobre o seu ofício que resulta em coautoria, ou seja, uma autoria de responsabilidades compartilhadas sobre o que estão produzindo. Para isso, Júlia começa o encontro no restaurante solicitando um relato de Beatriz sobre o andamento da aula, já que o trabalho de Beatriz agora também é um trabalho com a participação de Júlia, ou seja, a aula de Literatura Brasileira II passa a ser uma responsabilidade compartilhada. Por sua vez, Beatriz pede esclarecimentos sobre os questionamentos que Júlia propõe, já que, para se constituírem como coautoras, é preciso estarem alinhadas. Para chegar a esse ponto, Beatriz faz perguntas que exigem de Júlia uma organização discursiva de seus conhecimentos, e as ideias de Beatriz são prontamente complementadas por Júlia com base em experiências que ela vê como análogas. Como resultados dessas ações e propósitos, chegam à elaboração de questões para a UD que constituirão a materialidade analítica do trabalho que vão apresentar no congresso.

As ações levadas a cabo por Beatriz e Júlia nesse evento de formação fazem parte das práticas sociais que constituem a construção, em coautoria, da comunicação e do resumo publicado nos anais do evento acadêmico. O resumo que acaba sendo gerado a partir das interações das participantes mostra uma culminação do tipo de trabalho que aqui apresentamos. No texto publicado nos anais do evento, as professoras assumem-se em sua dimensão de autoras-formadoras destacando a inserção do trabalho em uma tradição de produção de conhecimento do PPE, identificam o nível avançado dos alunos e o período de aplicação do material em sala de aula. Destacam os paradigmas teóricos que as orientam, especialmente calcados nos usos sociais da linguagem, e detalham como a UD desenvolvida corresponde a esses paradigmas e como o material, inspirado em uma obra de literatura, estabelece uma ponte entre estudos da linguagem e a perspectiva de marginalidade na produção literária brasileira. O texto produzido, apesar de não ser um foco específico de análise aqui, configura-se como o resultado final do engajamento em construção de coautorias, fundamental para entender como um evento de formação é uma etapa no desenvolvimento de letramentos acadêmicos e na construção de conhecimentos e das identidades de professoras-autoras formadoras.

Esse tipo de engajamento mútuo em construção de coautoria também traz impactos para o desenvolvimento profissional. Conforme afinam seus discursos, vão construindo entendimentos singulares sobre o que estão vivendo tendo em vista um produto final que será tanto a unidade didática em si, que poderá ser utilizada por outro professor, como as explicações e justificativas teóricas para o material construído, que poderão servir para uma formação mais robusta de professores menos experientes na área. Assim, constroem uma possibilidade de enriquecer seus currículos profissionais ao projetar uma apresentação em 
congresso e a publicação de resumo nos anais do evento, e, em termos concretos no momento da reunião, a possibilidade da negociação de identidades de professoras-autoras-formadoras. Ser professora-autora-formadora não reside apenas no empreendimento de ter seu trabalho apresentado e/ou publicado, trata-se mais do que simplesmente uma meta a cumprir, tratase de um modo de ser e de lidar com a identidade profissional. Tais modos promovem a construção de trajetórias paradigmáticas no PPE, isto é, um tipo de experiência de aprendizagem que modela os empreendimentos mais basilares de uma instituição acadêmica: a construção de conhecimento singular e de impacto social. É fundamental destacar que ser professor-autor-formador não é um limite nem uma fronteira nas identidades das participantes, não se trata de uma identidade fixa ou porto de chegada final. Como professoras-autoras, as participantes podem atualizar suas identidades contingentemente em diferentes eventos. $O$ que as diferencia é o projeto pessoal e profissional que toma o espaço organizacional do PPE como plataforma para a materialização de reflexões conjuntas sobre a ação.

Essas identidades não são privilégio somente de mestrandos e doutorandos como Júlia e Beatriz. O que parece criar caminhos para a autoria-formadora é a oportunidade de alianças com outros colegas produzindo coautoria. Beatriz e Júlia renovam essa prática com a singularidade de seu próprio projeto que envolve a intersecção entre literatura, usos da linguagem e cultura brasileira, e adicionam camadas a tais relações como elaboração de material didático, a sala de aula de português para estrangeiros, os pontos de vista de cada uma e os pontos de vista conjuntamente elaborados sobre os temas, o que também são camadas que estruturam a cultura de formar-se como professor-autor-formador. A importância da participação do outro na construção de conhecimento e nas práticas acadêmicas é ressaltada por Lillis (2001):

[...] o envolvimento ativo de participantes em pesquisa tem um efeito mais fundamental sobre as formas em que construímos conhecimento, ajudando a evitar qualquer categorização fácil da experiência do "outro". Isso ocorre por duas razões: em primeiro lugar, porque os participantes, ou "outros", estão ativamente envolvidos na construção dessa experiência, de modo mais óbvio, ao contribuir, conferir, criticar as perspectivas do pesquisador; em segundo lugar, e de modo menos óbvio, porque os participantes e suas perspectivas tornam-se parte do diálogo interno da pesquisadora sobre o que ela está olhando e por quê (LILLIS, 2001, p. 12).

Esse último ponto, segundo a autora, diz respeito à importância das noções bakhtinianas de dialogicidade e endereçamento para a atribuição de sentidos e para a construção de textos potencialmente adequados às condições de produção e valorizados nas comunidades de prática nas quais se deseja ou precisa participar (LILLIS, 2001, p. 41). Desde essa perspectiva, as práticas dialógicas em que Beatriz e Júlia se engajam na discussão sobre a UD e na elaboração do resumo da apresentação de sua experiência profissional possibilitam a construção de um entendimento mútuo, construído cultural, local e situadamente, sobre 
seis questões básicas, organizadas em três grupos, para uma participação crítica e autoral: "Quem você pode ser? Quem você quer ser?"; "O que você pode dizer? O que você quer dizer?"; “Como você pode dizer? Como você quer dizer?" (LILLIS, 2001, p. 51).

\section{Considerações finais}

Neste trabalho analisamos a trajetória de professor-autor-formador como uma trajetória construída com atividades de professor-autor (justificar escolhas, responder pela própria singularidade produzida) mobilizadas para um projeto de registro das aprendizagens como professores visando à formação de outros professores em um congresso na área. $A$ abordagem da formação do professor-autor-formador é a de um profissional que explicita e analisa a prática distanciando-se do calor da ação (GARCEZ; SCHLATTER, 2017; SCHÖN, 1983; 2000). Assim, investiga-se o vivido, caminhos são reconstruídos e ressignificados, há reflexões concretizadas em interlocução, ampliando a própria aprendizagem e valorizando o singular, o saber descritivo antes que a prescrição de saberes, em um exercício de racionalidade crítica (BARBOSA, 2000). O registro das práticas nessa perspectiva aponta para "uma troca de saberes diversos, construídos em espaços singulares para tomar decisões em relação a desafios específicos, podendo justificar as decisões tomadas e responsabilizar-se pela singularidade produzida" (GARCEZ; SCHLATTER, 2017, p. 31).

O professor-autor-formador articula o diálogo entre conhecimentos de diferentes ordens e o expõem a interlocutores previamente projetados, reificando na forma de textos um conjunto de discursos e ações que compõem o seu fazer pedagógico. Um ponto fundamental dessa proposição é que o professor desenvolva um olhar crítico para as singularidades das suas práticas, por meio da reflexão-sobre-a-ação e sobre-a-reflexão-sobrea-ação (SCHÖN, 1983), o que está sugerido como prática no PPE pela produção acadêmica que toma o programa como cenário. O que argumentamos é que se engajar em eventos de formação que visem à produção de conhecimento novo, baseado nas singularidades da prática, é um modo de construir uma trajetória paradigmática no PPE como professor-autorformador.

Conversar com os colegas é central na construção de tais identidades; expor suas visões, questionamentos, justificativas e narrativas integra uma rede de ações em interlocução que cria oportunidades e desafios. A concretização não está apenas no texto publicado, mas também nas coleções de conversas que vão construindo uma memória local do trabalho dos professores. Os professores aprendem no PPE à medida que passam a compartilhar de tal memória de práticas. Constituem-se como professores-autores conforme vão percebendo o decisivo papel da narrativa de experiências para o andamento das práticas de um coletivo que valoriza a inovação e o trabalho colaborativo, e isso vai abrindo a possibilidade de registrar narrativas e justificativas. 
Nos eventos de formação, os professores transitam em construção de autoria e coautoria e, em alguns casos, podem interferir nas práticas futuras de outros professores atuando como professores-autores-formadores. O que inicia em interações orais, passa pelo escrutínio das ideias e ganha forma de texto escrito. Desse modo, produzem novas interlocuções e, como no exemplo analisado e outros que compõem o quadro de publicações do PPE, concentram-se em refletir e analisar uma experiência pedagógica que é considerada pelos participantes-autores como suficientemente bem-sucedida a ponto de poder integrar uma rede de produções sobre a área. Neste sentido os próprios professores mostram que, ao produzirem seus materiais didáticos, registros sobre sua prática e textos acadêmicos (comunicação em congresso, artigo científico, trabalho de conclusão de curso de graduação e de pós-graduação), administrando um nível de autonomia no trabalho de que desfrutam, construindo com seus pares significados comuns e negociando discursos valorizados no seu local de trabalho, adequando seu discurso para endereçá-lo a uma comunidade acadêmica e profissional mais ampla, entendem-se como produtores de conhecimento novo sobre a área de PLA e participantes autorais que podem contribuir na formação de colegas e transformar espaços de atuação profissional.

\section{Referências}

BARBOSA, M. Racionalidades e papel do educador: perspectiva simples e abordagem complexa. In: Diversidade e identidade: 1a Conferência Internacional de Filosofia da Educação. Porto: Universidade do Porto, Faculdade de Letras, 2000. p. 329-338.

BULLA, G. S. Relações entre design educacional, atividade e ensino de português como língua adicional em ambientes digitais. Tese (Doutorado em Letras). Porto Alegre: Universidade Federal do Rio Grande do Sul, 2014.

CONCEIÇÃO, J. V. O ensino de gêneros orais públicos: o que o teatro tem a ver com isso? Trabalho de Conclusão de Curso (Graduação em Letras). Porto Alegre: Universidade Federal do Rio Grande do Sul, 2011.

COSTA, E. V. Práticas de formação de professores de português língua adicional em um Instituto Cultural Brasileiro no exterior. Dissertação (Mestrado em Letras). Porto Alegre: Universidade Federal do Rio Grande do Sul, 2013.

COSTA, E. V. Eventos de formação de professores de português como língua adicional: a organização das práticas e as trajetórias de participação em um estudo interpretativo sobre aprender a ensinar. Tese (Doutorado em Letras). Porto Alegre: Universidade Federal do Rio Grande do Sul, 2018.

COSTA, E. V.; SCHLATTER, M. Eventos de formação de professores: uma perspectiva etnográfica sobre aprender a ensinar. Trabalhos em Linguística Aplicada, v. 56, n. 1, p. 37-63, 2017. https://doi.org/10.1590/010318135173200451 
FORNARI, M. K. O texto literário na aula de língua estrangeira: um olhar, uma possibilidade, uma experiência. Trabalho de Conclusão de Curso (Graduação em Letras). Porto Alegre: Universidade Federal do Rio Grande do Sul, 2006.

FONSECA, C. Quando cada caso NÃO é um caso: Pesquisa etnográfica e educação. Revista Brasileira de Educação, n. 10, p. 58-79, 1999.

GARCEZ, P. M.; SCHLATTER, M. Professores-autores-formadores: Princípios e experiências para a formação de profissionais de educação linguística. In: MATEUS, E; TONELLI, J. R. A. (org.) Diálogos (im)pertinentes entre formação de professores e aprendizagem de línguas. São Paulo: Blucher, 2017. p. 13-36. https://doi.org/10.5151/9788580392708-01

KORHONEN, H.; HEIKKINEN H. L.T.; KIVINIEMI U.; TYNJÄLÄ, P. Student teachers' experiences of participating in mixed peer mentoring groups of in-service and pre-service teachers in Finland. Teaching and Teacher Education, 61, p. 153-163, 2017. https://doi.org/10.1016/j.tate.2016.10.011

KRAEMER, F. F. Português língua adicional: progressão curricular com base em gêneros do discurso. Dissertação (Mestrado em Letras). Porto Alegre: Universidade Federal do Rio Grande do Sul, 2012.

LILLIS, T. M. Student writing: Acess, regulation, desire. Londres: Routledge, 2001. https://doi.org/10.4324/9780203186268

NÓVOA, A. Os professores e a sua formação. Lisboa: Dom Quixote, 1995.

NÓVOA, A. O regresso dos professores. In: Conferência Desenvolvimento profissional de professores para a qualidade e para a equidade da Aprendizagem ao longo da Vida. Lisboa: Presidência Portuguesa do Conselho da União Europeia, 2007.

PÉREZ GÓMEZ, A. O pensamento prático do professor: a formação do professor como profissional reflexivo. In: NÓVOA, A. (Org.). Os professores e a sua formação. Lisboa: Dom Quixote, 1995. p. 93-114.

SCHLATTER, M. Reflexão sobre a prática de ensino de LE: ação individual ou coletiva? In: MASELLO, L. (Org.). Portugués lengua segunda y extranjera en Uruguay: Actas del Primero Encuentro de Profesores de Portugués Lengua Extranjera de Uruguai. Montevideo: Departamento de Publicaciones de la Facultad de Humanidades y Ciencias de la Educación UDELAR, 2008. p. 59-63.

SCHLATTER, M.; GARCEZ, P. M. Línguas adicionais na escola: Aprendizagens colaborativas em Inglês. Erechim: EDELBRA, 2012.

SCHLATTER, M.; GARCEZ, P. M. Portuguese as an additional language: global trends in local actions. In: CAVALCANTI, M. C.; MAHER, T. M. (Org.) Multilingual Brazil: Language resources, identities and ideologies in a globalized world. New York/London: Routledge, 2018. p. 211224.

SCHÖN, D. The reflective practitioner: How professionals think in action. London: Temple Smith, 1983.

SCHÖN, D. Educando o profissional reflexivo: um novo design para o ensino e aprendizagem. Porto Alegre: ARTMED, 2000. 
SILVA, M. C.; LEURQUIN, E. V. L. F. Experiência de formação docente e de elaboração de material didático para o ensino e aprendizagem de português como língua estrangeira. In: Simpósio Internacional de Língua Portuguesa, v. único. Uberlândia: Editoras universitárias, 2014. p. 36-55.

SOUZA, J. P. C. Letra e Música: uma proposta para o ensino da canção na aula de português como língua adicional. Tese (Doutorado em Letras). Porto Alegre: Universidade Federal do Rio Grande do Sul, 2014.

WENGER, E. Communities of practice. New York: Cambridge University Press, 1998. https://doi.org/10.1017/CB09780511803932

ZEICHNER, K. Rethinking the connections between campus courses and field experiences in college and university-based teacher education. Journal of Teacher Education, v. 61, p. 89-99, 2010. https://doi.org/10.1177/0022487109347671 